\title{
Chemoradiation as a nonsurgical treatment option for early-stage esophageal cancers: a retrospective cohort study
}

\author{
Ranjan Pathak ${ }^{1}$, Maureen E. Canavan ${ }^{2}$, Samantha Walters ${ }^{3}$, Michelle C. Salazar ${ }^{3}$, Daniel J. Boffa ${ }^{2,3}$ \\ ${ }^{1}$ Department of Medical Oncology and Therapeutics Research, City of Hope, Duarte, CA, USA; ${ }^{2}$ Cancer Outcomes, Public Policy and Effectiveness \\ Research (COPPER) Center, Yale School of Medicine, CT, USA; ${ }^{3}$ Section of Thoracic Surgery, Department of Surgery, Yale School of Medicine, \\ New Haven, CT, USA \\ Contributions: (I) Conception and design: R Pathak, DJ Boffa; (II) Administrative support: None; (III) Provision of study materials or patients: None; \\ (IV) Collection and assembly of data: None; (V) Data analysis and interpretation: All authors; (VI) Manuscript writing: All authors; (VII) Final \\ approval of manuscript: All authors. \\ Correspondence to: Daniel J. Boffa, MD. Section of Thoracic Surgery, Department of Surgery, Yale School of Medicine, 330 Cedar St, BB205, PO Box \\ 208062, New Haven, CT 06520-8062, USA. Email: Daniel.boffa@yale.edu.
}

\begin{abstract}
Background: Complete tumor removal via esophagectomy or endoscopic excision has been associated with the greatest survival in early-stage esophageal cancer. However, patient health, anatomy, or goals of care may render patients ineligible for excision or resection. In this setting, chemoradiation (CRT) may be considered as a nonsurgical approach, however the outcomes associated with CRT in early-stage esophageal cancer are incompletely understood.

Methods: The National Cancer Database was queried for treatment-naïve cT1/T2, N0, M0 esophageal cancer patients managed with concurrent multi-agent CRT ( $\geq 50$ Gy) between 2004 and 2015. Medically inoperable patients were excluded. Kaplan-Meier curves were generated to estimate 5 -year overall survival (OS) from diagnosis in both stages.

Results: Of the 828 patients identified, 279 were cT1 and 549 were cT2. For cases after 2010, cT1 $(\mathrm{N}=124)$ was further stratified in cT1a $(\mathrm{N}=32,25.8 \%)$ and cT1b $(\mathrm{N}=46,37.1 \%)$. Kaplan-Meier estimates demonstrated a 5 -year survival of $21.7 \%$ for cT1 and $25.9 \%$ for cT2. Sensitivity analyses were performed to mitigate competing survival risk from poor health. Among 589 comorbidity-free patients (i.e., Charlson = score zero), the 5 -year survival with CRT was $23.4 \%$ for cT1 and $27.8 \%$ for cT2. Finally, a subset of patients who refused a recommended surgery were evaluated with 5 -year survival cT1 $=33.5 \%$ and cT2 $=33.4 \%$ ).

Conclusions: Up to a third of selected patients with early-stage esophageal cancer may be cured after CRT as definitive non-surgical treatment. However, cure rates may be underestimated in this setting, secondary to persistent health-related bias.
\end{abstract}

Keywords: Esophageal cancer; national cancer database; definitive chemoradiotherapy; nonsurgical management; survival

Submitted Mar 05, 2020. Accepted for publication Jun 09, 2020.

doi: $10.21037 /$ jtd-20-1187

View this article at: http://dx.doi.org/10.21037/jtd-20-1187

\section{Introduction}

Globally, esophageal cancer remains the $6^{\text {th }}$ leading cause of cancer-related deaths, with estimated 572,000 newly diagnosed cases resulting in over 508,000 deaths in 2018 (1). While the incidence of several cancer types is expected to decrease over the next decade, the global incidence of esophageal cancer is expected to increase by almost $140 \%$ (2). As a result, there is an international urgency to efforts to improve the management of esophageal cancer.

Perhaps the greatest optimism for improving the fate of esophageal cancer centers around early-stage esophageal 
cancer. Currently, around a quarter of esophageal cancers present with cancer confined to the esophagus, with partial thickness involvement of the esophageal wall (i.e., T12,N0M0) (3). In this setting, complete tumor removal via esophagectomy has been associated with the highest cure rates, and has historically represented the standard of care $(4,5)$.

Unfortunately, esophagectomy represents a particularly complex surgical procedure in which morbidity is common (e.g., roughly $30 \%$ of patients will have a major complication) (6), and the mortality rate is high (e.g., more than twice that of colon resection for colon cancer) (7). In fact, many early-stage patients may be considered ineligible for esophagectomy because of health-related concerns (i.e., comorbidities, poor performance status, nutritional status). Finally, some patients are simply unwilling to undergo complex surgery, a prolonged recovery, and lifestyle changes intrinsic to esophagectomy, as these are not congruent with their goals of care. Therefore, a need exists for non-surgical alternatives to definitively treat early-stage esophageal cancer.

More recently endoscopic therapy (e.g., radiofrequency ablation, endoscopic mucosal resection, cryotherapy) has evolved to address select subsets of early-stage esophageal cancer with extremely encouraging results. As such, endoscopic therapy has been embraced by many as the standard of care for the earliest stage esophageal cancer for tumor limited to the mucosa (i.e., T1a), or perhaps the very beginning of the submucosa (T1b-SM1) $(5,8)$. On the other hand, endoscopic therapies are not appropriate for all patients with early-stage esophageal cancer. Tumors invading into the deeper submucosa or beyond (most T1b and T2) would be considered ineligible for endoscopic therapy. Furthermore, there are several highrisk features that make endoscopic therapy less appealing (i.e., lymphovascular invasion, poor differentiation, multifocality, involvement of greater proportions of the circumference). As a result, there remains a need for additional non-surgical approaches to early-stage esophageal cancer.

The National Cancer Database (NCDB) is a comprehensive database that captures the care of approximately $75 \%$ of newly diagnosed esophageal cancer patients in the United States with detailed staging data, treatments and long-term follow-up (9). The survival associated with chemoradiation (CRT) for cT1 and T2 N0, M0 esophageal cancer was evaluated as a reflection of the potent of CRT to serve as a non-surgical treatment option for early stage esophageal cancer.
We present the following article in accordance with the Strengthening the Reporting of Observational Studies in Epidemiology (STROBE) guidelines for reporting observational studies (10) (Available at http://dx.doi. org/10.21037/jtd-20-1187).

\section{Methods}

\section{Data source}

The NCDB is a hospital-based tumor registry jointly managed by the American College of Surgeons and the American Cancer Society (11). The NCDB uses deidentified data and was therefore deemed exempt by the Yale University Institutional Review Board.

\section{Study population}

A query of the NCDB Participant User File from 2004 to 2016 was performed for treatment-naive patients 20 years or older with esophageal cancers managed with concurrent CRT. Only patients with clinical stage T1-2N0M0 tumors with available survival data, who underwent concurrent CRT with multi-agent chemotherapy and radiation dose $\geq 50 \mathrm{~Gy}$, for whom the diagnosis of esophageal cancer represented their first malignancy were included. In order to mitigate bias arising from the tendency of unhealthy patients receiving nonsurgical therapy, all medically inoperable patients who were noted as: "surgery was not recommended/performed because it was contraindicated due to patient risk factors (comorbid conditions, advanced age, etc.)" were excluded (Figure 1).

\section{Analytic cohorts}

\section{Definitive CRT cohort}

All non-surgical patients that had undergone definitive CRT for esophageal cancer were included. CRT was defined as multi-agent chemotherapy started within 14 days of the initiation of radiation therapy. Radiation dose $\geq 50$ Gy was considered to be a definitive dose as per the National Comprehensive Cancer Network guidelines (5).

\section{Sensitivity cohorts}

In an effort to mitigate the bias of unhealthy patients receiving definitive CRT, two sensitivity analyses were performed. First, the survival analyses were performed in a subset of comorbidity-free patients (i.e., Charlson score of 


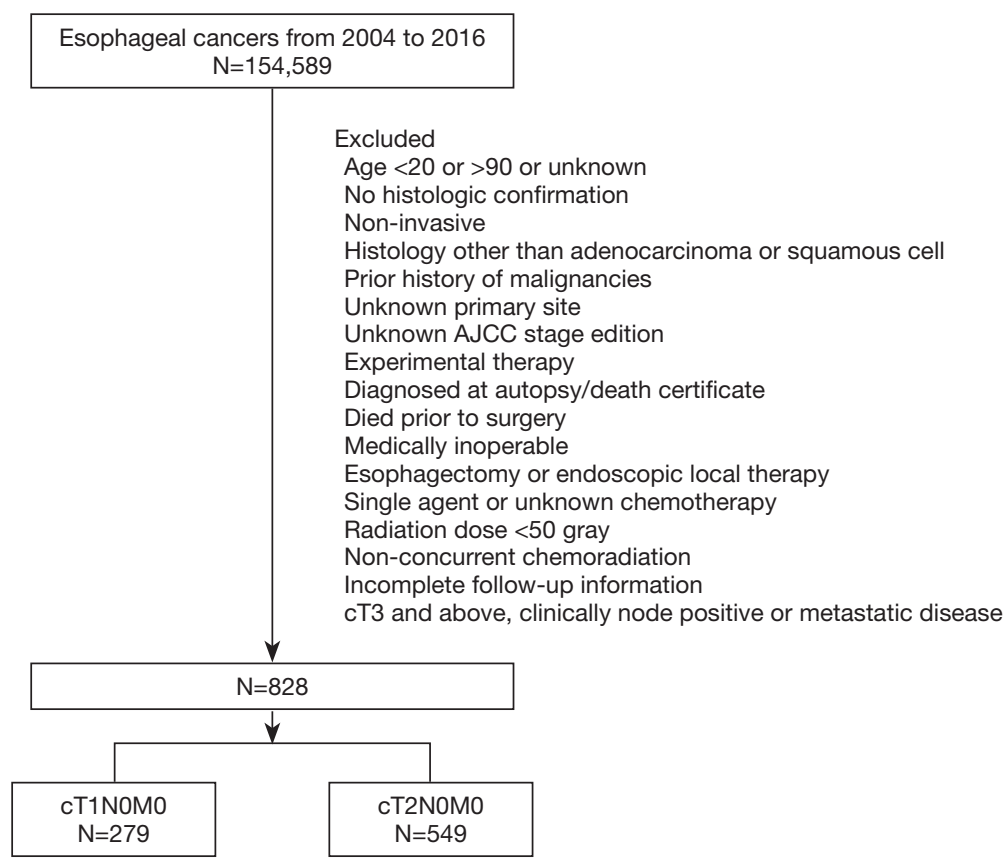

Figure 1 Diagram of study cohort selection steps.

zero). Next, in a further effort to ensure the health of the CRT population, the subset of early-stage esophageal cancer patients that had been recommended to undergo surgery, but refused, were studied (coded as "surgery of the primary site was not performed; it was recommended by the patient's physician, but this treatment was refused by the patient, the patient's family member, or the patient's guardian"). These patients were, in theory, healthy enough to be considered surgical candidates, as surgery was recommended.

\section{Reference subset}

In an effort to provide a reference for outcomes of nonsurgically managed patients in this dataset, a surgical population was studied of patients with cT1 and cT2 tumors that were managed via esophagectomy during this time frame.

\section{Data elements}

The following independent variables were included in the descriptive analyses: age, sex, race, Hispanic origin, insurance status, income (i.e., median income of the patient's zip code area), education (percentage of people in the patient's zip code without high school diploma), area of residence (based on patient's reported county and state), distance (great circle distance in miles between the patient's residence and the reporting hospital), facility type (academic or non-academic) and location, Charlson-Deyo score, year of diagnosis, tumor primary site and histological type and grade.

The study period was affected by a transition from the $6^{\text {th }}$ edition to the $7^{\text {th }}$ edition of the AJCC staging system, reflected in the NCDB starting in 2010. Patients coded prior to 2010 did not contain sufficient staging data for conversion to the $7^{\text {th }}$ AJCC edition, therefore a homogenous study group was created by converting patients diagnosed between 2010 and 2015 to the corresponding $6^{\text {th }}$ edition stage.

\section{Missing data strategy}

Overall, the rates of missing data were low (Table 1). Multiple imputation via chained equations was used to address missing data that appeared to be missing at random (12). Rubin's rules were used to generate pooled effect estimates and variance across imputed data sets (13).

Overall survival (OS) was determined from the start of chemotherapy to the date of death or last follow up. The study was landmarked at 5 weeks, (median time to adjuvant chemotherapy after diagnosis) in an effort to mitigate immortal time bias. A complete list of variables collected in the NCDB is available online (14). 
Table 1 Baseline characteristics of cT1N0M0 versus cT2N0M0 patients

\begin{tabular}{|c|c|c|c|}
\hline Characteristic & $\begin{array}{c}\text { cT1N0M0 } \\
(\mathrm{N}=279)\end{array}$ & $\begin{array}{c}\text { cT2N0M0 } \\
(\mathrm{N}=549)\end{array}$ & $\mathrm{P}$ \\
\hline Median age [IQR], years & 70 [62-77] & 70 [61-78] & 0.78 \\
\hline Age category & & & 0.78 \\
\hline$<65$ & 93 (33.33) & $186(33.88)$ & \\
\hline 65 to 74 & $86(30.82)$ & $179(32.6)$ & \\
\hline$\geq 75$ & $100(35.84)$ & $184(33.52)$ & \\
\hline Sex & & & 0.001 \\
\hline Male & $191(68.46)$ & $431(78.51)$ & \\
\hline Female & $88(31.54)$ & $118(21.49)$ & \\
\hline Race & & & 0.006 \\
\hline White & $227(81.36)$ & 485 (88.34) & \\
\hline Non-white & $52(18.64)$ & $64(11.66)$ & \\
\hline Origin & & & 0.07 \\
\hline Non-Hispanic & $261(93.55)$ & $486(88.52)$ & \\
\hline Hispanic & $\mathrm{b}$ & $16(2.91)$ & \\
\hline Unknown & $13(4.66)$ & $47(8.56)$ & \\
\hline Insurance & & & 0.20 \\
\hline Not insured & $13(4.66)$ & $22(4.01)$ & \\
\hline Private insurance & 55 (19.71) & $142(25.87)$ & \\
\hline Medicaid & $26(9.32)$ & $32(5.83)$ & \\
\hline Medicare & $177(63.44)$ & $335(61.02)$ & \\
\hline Other government & b & $10(1.82)$ & \\
\hline Unknown & $\mathrm{b}$ & b & \\
\hline Facility type & & & 0.93 \\
\hline Nonacademic ${ }^{c}$ & 212 (75.99) & $414(75.41)$ & \\
\hline Academic & $67(24.01)$ & 135 (24.59) & \\
\hline Facility location & & & 0.05 \\
\hline Northeast & $44(15.77)$ & $106(19.31)$ & \\
\hline Midwest & $72(25.81)$ & $179(32.6)$ & \\
\hline South & $118(42.29)$ & $193(35.15)$ & \\
\hline West & 45 (16.13) & 71 (12.93) & \\
\hline Area of residence ${ }^{d}$ & & & 0.11 \\
\hline Rural & $b$ & $18(3.28)$ & \\
\hline Urban & $41(14.7)$ & 109 (19.85) & \\
\hline Metropolitan & $216(77.42)$ & $409(74.5)$ & \\
\hline Unknown & $13(4.66)$ & $13(2.37)$ & \\
\hline
\end{tabular}

Table 1 (continued)
Table 1 (continued)

\begin{tabular}{|c|c|c|c|}
\hline Characteristic & $\begin{array}{c}\text { cT1N0M0 } \\
(\mathrm{N}=279)\end{array}$ & $\begin{array}{c}\text { cT2N0M0 } \\
(\mathrm{N}=549)\end{array}$ & $\mathrm{P}$ \\
\hline Distance & & & 0.20 \\
\hline$\leq 10$ & $168(60.22)$ & 295 (53.73) & \\
\hline 10 to 20 & $41(14.7)$ & $113(20.58)$ & \\
\hline 20 to 50 & $49(17.56)$ & $106(19.31)$ & \\
\hline 50 to 100 & $10(3.58)$ & $20(3.64)$ & \\
\hline$>100$ & $11(3.94)$ & $15(2.73)$ & \\
\hline Median income & & & 0.29 \\
\hline$<38,000$ & $64(22.94)$ & $98(17.85)$ & \\
\hline 38,000 to 47,999 & $85(30.47)$ & $162(29.51)$ & \\
\hline 48,000 to 62,999 & $69(24.73)$ & $146(26.59)$ & \\
\hline$>63,000$ & $57(20.43)$ & $138(25.14)$ & \\
\hline Unknown & b & $\mathrm{b}$ & \\
\hline Education, $\%^{\mathrm{e}}$ & & & 0.06 \\
\hline$\geq 21$ & $59(21.15)$ & $85(15.48)$ & \\
\hline 13 to 20.9 & $77(27.6)$ & $151(27.5)$ & \\
\hline 7 to 12.9 & 106 (37.99) & 206 (37.52) & \\
\hline$<7$ & $34(12.19)$ & $104(18.94)$ & \\
\hline Unknown & b & $\mathrm{b}$ & \\
\hline Year of diagnosis & & & 0.05 \\
\hline 2004 & $25(8.96)$ & $40(7.29)$ & \\
\hline 2005 & $25(8.96)$ & $29(5.28)$ & \\
\hline 2006 & $20(7.17)$ & $31(5.65)$ & \\
\hline 2007 & $21(7.53)$ & $25(4.55)$ & \\
\hline 2008 & $26(9.32)$ & $45(8.2)$ & \\
\hline 2009 & $38(13.62)$ & $43(7.83)$ & \\
\hline 2010 & $23(8.24)$ & $52(9.47)$ & \\
\hline 2011 & $16(5.73)$ & $47(8.56)$ & \\
\hline 2012 & $19(6.81)$ & $62(11.29)$ & \\
\hline 2013 & $14(5.02)$ & $51(9.29)$ & \\
\hline 2014 & $25(8.96)$ & $54(9.84)$ & \\
\hline 2015 & 27 (9.68) & $70(12.75)$ & \\
\hline Histology & & & 0.23 \\
\hline Adenocarcinoma & $121(43.37)$ & $206(37.52)$ & \\
\hline Squamous cell carcinoma & $144(51.61)$ & 318 (57.92) & \\
\hline Other & 14 (5.02) & $25(4.55)$ & \\
\hline
\end{tabular}

Table 1 (continued) 
Table 1 (continued)

\begin{tabular}{|c|c|c|c|}
\hline Characteristic & $\begin{array}{c}\text { cT1N0M0 } \\
(\mathrm{N}=279)\end{array}$ & $\begin{array}{c}\text { cT2N0M0 } \\
(\mathrm{N}=549)\end{array}$ & $\mathrm{P}$ \\
\hline Primary site & & & 0.18 \\
\hline Upper esophagus & $28(10.04)$ & $30(5.46)$ & \\
\hline Middle esophagus & $51(18.28)$ & $101(18.40)$ & \\
\hline Lower esophagus & $156(55.91)$ & $318(57.92)$ & \\
\hline Overlapping & $10(3.58)$ & $21(3.83)$ & \\
\hline Esophagus, NOS & $34(12.19)$ & 79 (14.39) & \\
\hline Grade & & & 0.17 \\
\hline Well differentiated & $16(5.73)$ & $37(6.74)$ & \\
\hline Moderately differentiated & $125(44.80)$ & $216(39.34)$ & \\
\hline $\begin{array}{l}\text { Poorly differentiated or } \\
\text { undifferentiated }\end{array}$ & 78 (27.96) & $192(34.97)$ & \\
\hline Unknown & $60(21.51)$ & $104(18.94)$ & \\
\hline Charlson-Deyo score & & & 0.07 \\
\hline 0 & $211(75.63)$ & $378(68.85)$ & \\
\hline 1 & $54(19.35)$ & $123(22.40)$ & \\
\hline$\geq 2$ & $14(5.02)$ & $48(8.74)$ & \\
\hline
\end{tabular}

Percentages might not add up to $100 \%$ due to approximation. ${ }^{a}$, for cases after 2010, T1 $(\mathrm{N}=124)$ was further stratified in T1a $(\mathrm{N}=32,25.8 \%)$ and $\mathrm{T} 1 \mathrm{~b}(\mathrm{~N}=46,37.1 \%)$ with missing substage in 46 patients (37.1\%); ${ }^{b}$, frequencies less than 10 not reported per National Cancer Database guidelines; ' , includes community cancer program, comprehensive community cancer program, integrated network cancer program, and other specified types of cancer programs; ${ }^{\text {d }}$, based on patient's zip code area; ${ }^{e}$, percent of people in the patient's zip code area with no high-school diploma. IQR, interquartile range; NOS, not otherwise specified.

\section{Statistical analysis}

Bivariate analyses were performed using the $\chi^{2}$ test for categorical variables (or Fisher exact test when appropriate) and the Student $t$-test for continuous variables. KaplanMeier curves were generated to provide estimates for OS.

Cox proportional hazards model were created to evaluate the predictors of mortality in cT1-2N0 patients treated with definitive CRT. These Cox models were adjusted for facility location, age, sex, insurance, income, education, primary site, histological type, grade, Charlson score as well as a hospital-specific random effect to account for hospital-level clustering (Table S1) $(15,16)$. Violations of the proportional hazards assumption were assessed graphically, and none were detected. All statistical analyses were performed using

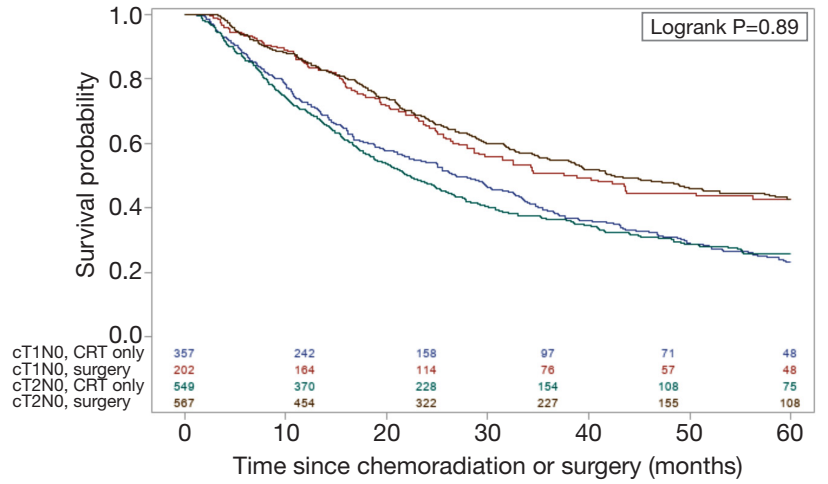

Figure 2 Kaplan-Meier plot of overall survival estimates for cT1N0 and cT2N0 patients treated with definitive chemoradiation and surgery. The number of patients at risk is indicated for time increments of 10 months. Blue line represents cT1N0 patients managed with definitive chemoradiation; red line represents cT1N0 patients managed with surgery; green line represents cT2N0 patients managed with definitive chemoradiation; brown line represents cT2N0 patients treated with surgery. CRT, chemoradiation.

SAS 9.4 (SAS Institute Inc., NC, USA).

\section{Results}

\section{Patient characteristics}

A total of 828 patients in the NCDB underwent definitive CRT for cT1-2N0M0 esophageal cancer between 2004 and 2015, including 279 cT1 and 549 cT2. Most patients $(589=71.1 \%)$ were free of comorbidities (i.e., Charlson score of zero). cT2N0M0 patients were more likely to be males $(\mathrm{P}=0.001)$ and whites $(\mathrm{P}=0.006)$ compared to $\mathrm{c} T 2 \mathrm{~N} 0 \mathrm{M} 0$ patients (Table 1).

\section{Survival}

Kaplan Meier analysis was performed with a median followup of 43.8 months among surviving patients. The fiveyear OS in cT1N0M0 and cT2N0M0 patients treated with definitive CRT was $21.7 \%$ and $25.9 \%$ ( $\log$-rank $\mathrm{P}=0.89$ ), with median survival of $26.1 \mathrm{vs}$. 22.0 months respectively (Figure 2). For reference in the NCDB dataset, the 5 -year OS in patients managed surgically was $48.7 \%$ in cT1 and $40.9 \%$ in $\mathrm{cT} 2$.

The adjusted survival analysis was conducted using Cox Proportional Hazards Models. Several risk factors were 


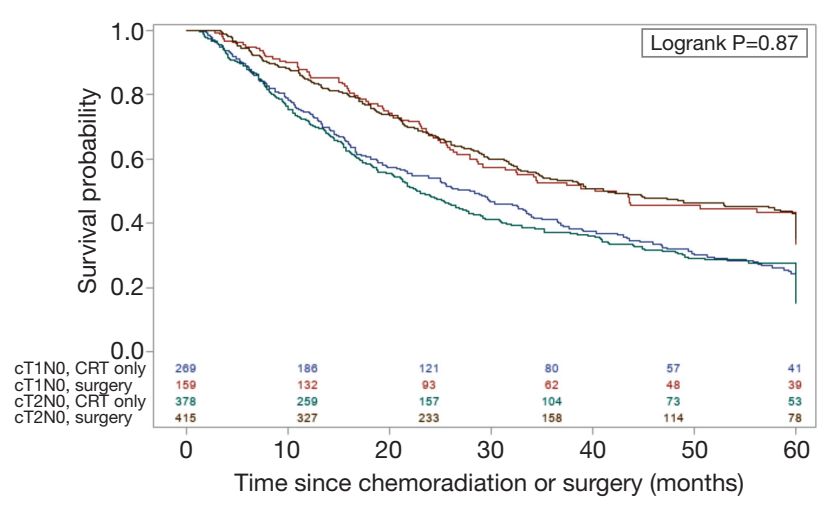

Figure 3 Kaplan-Meier plot of overall survival estimates for cT1N0 and cT2N0 patients treated with definitive chemoradiation and surgery with Charlson score of zero. The number of patients at risk is indicated for time increments of 10 months. Blue line represents cT1N0 patients managed with definitive chemoradiation; red line represents cT1N0 patients managed with surgery; green line represents cT2N0 patients managed with definitive chemoradiation; brown line represents cT2N0 patients treated with surgery. CRT, chemoradiation.

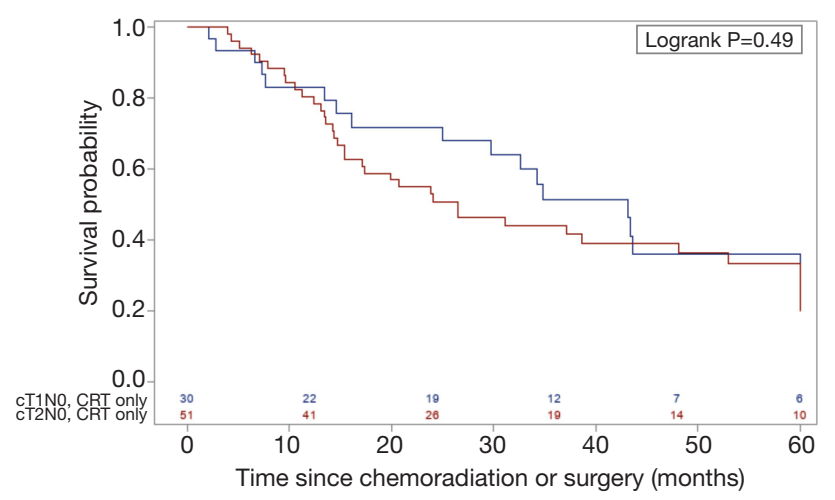

Figure 4 Kaplan-Meier plot of overall survival estimates for cT1N0 and cT2N0 patients treated with definitive chemoradiation who refused surgery despite being recommended. The number of patients at risk is indicated for time increments of 10 months. Blue line represents cT1N0 patients managed with definitive chemoradiation; red line represents cT1N0 patients managed with surgery; green line represents cT2N0 patients managed with definitive chemoradiation; brown line represents cT2N0 patients treated with surgery. CRT, chemoradiation.

identified. Age $\geq 75$ years, lack of insurance, increased distance from the treatment center, squamous cell carcinoma, poorly differentiated histology and higher Charlson score were independently associated with increased mortality in patients undergoing definitive CRT (Table S1).

\section{Sensitivity analyses among healthier patients}

In an attempt to mitigate the impact of the competing survival risk of poorer patient health (as nonsurgical patients tend to be less healthy), the subset of patients in whom no comorbidities were identified (i.e., Charlson score zero) was studied. Among comorbidity-free patients with early-stage esophageal cancer managed with CRT, the 5-year survival was $23.4 \%$ for cT1N0M0 and $27.8 \%$ for cT2N0M0, with median survival of 29.1 vs. 23.0 months respectively, (Logrank $\mathrm{P}=0.87$ ) (Figure 3).

As a separate approach to studying healthier patients, the subset of patients who refused a recommended surgery (i.e., were felt to be surgical candidates, but instead elected to have CRT) were studied ( $\mathrm{N}=83,10.1 \%)$. The 5-year survival of patients refusing a recommended surgery was $33.5 \%$ for cT1N0M0 and $33.4 \%$ for cT2N0M0, with a median OS of 43.1 and 26.5 months, respectively (Log-rank $\mathrm{P}=0.49$ ) (Figure 4 and Table S1).

\section{Discussion}

Overall, between a quarter and a third of patients with early-stage esophageal cancer achieved a 5 -year survival estimate typically associated with cure. This survival rate is considerably lower than what has been reported for similarly staged subsets that were managed surgically (average of $50-70 \% 5$-year survival) was well as those managed endoscopically (average of $80-85 \% 5$-year survival) (17-20). This likely reflects a combination of differential ability to achieve local control (21), as well as health-related bias, as CRT has historically been a preferential treatment approach for patients that were not healthy enough for surgery. This potential has likely dissipated in part over time with the emergence of endoscopic therapies, which can be performed on a wide range of patients including those in poor health. However, for the subset that are ineligible for endoscopic treatment because of tumor depth or other tumor attributes (i.e., poor differentiation) CRT will likely be disproportionately populated with poorer health patients.

It is unclear how these findings mesh with existing data on the outcomes associated with definitive CRT for locoregionally confined cancer. More specifically, the randomized trials comparing CRT followed by surgery, to 
definitive CRT, identified a 2-year survival rate of $\sim 35 \%$, which is similar when compared to the current study $(22,23)$. On the other hand, patients in the randomized trials had more advanced tumors (patients were at least cT3 or above) $(22,23)$. Prior observational studies have estimated the 5 -year survival with CRT to be approximately 20\%, which is similar to our study (24-27).

There was a trend towards improved survival with increasing efforts to mitigate health related bias. More specifically, there was a modest increase in survival as the study population was concentrated with healthier patients. The comorbidity free patients experienced superior survival and the patients who refused a recommended surgery even better. Because of this, we suspect that health related bias may continue to compromise the survival of the CRT cohort. This is relevant for the healthy patient that simply does not want to undergo esophagectomy to meet their goals of care. In this case, we would estimate that survival might be even higher than what is currently predicted.

The outcomes of early stage esophageal cancer managed with surgery were given as reference to allow readers to understand the general outcomes within this population in the NCDB. We recognize the tendency to interpret this as evidence towards comparative effectiveness of surgery versus definitive CRT (i.e., surgery associated with superior long-term survival). We caution against using the presented data to draw this type of conclusion, as the studies were not designed to balance the confounding risk factors in the surgical and nonsurgical cohorts. We do believe this reference is useful in calibrating the outcomes of esophageal cancer patients within the NCDB with other large datasets.

\section{Limitations}

Our study has several limitations beyond what are typically associated with observational research. The accuracy of the stage determination was unclear, as the NCDB does not capture the extent of the clinical staging evaluation (i.e., endoscopic ultrasound and PET scan use). Therefore, it is possible that some patients were in reality more advanced than what was characterized. In the latter years the survival did increase a bit, which would support the possibility that enhanced stage evaluation was an opportunity to achieve superior outcomes. In addition, the specific type of chemotherapeutic agents was not captured. Certain regimens may have greater activity in esophageal cancer and affect the overall outcome in this cohort. Similarly, the number of chemotherapy cycles administered was unknown.
We were able to restrict the population to patients receiving "multi-agent" chemotherapy, which is an important aspect of current treatment paradigms. Despite attempts to mitigate health bias, we must assume that patients that refused local therapy likely had health related issues (perhaps not documented) that also threatened their survival. Attempts were made to mitigate this bias by restricting our analysis to Charlson zero patients and patients that refused surgery. Although the surgery was recommended but "refused by the patient, the patient's family member, or the patient's guardian," there was no specific reason for refusal noted in the NCDB and no documentation over who deemed the patient a surgical candidate (i.e., the patient's internist or surgeon). Finally, we would not be able to distinguish patients who were planned to have CRT followed by surgery, and then developed a complication that rendered them ineligible to continue. This would likely only relate to cT2N0M0 patients, in whom trimodality therapy is a commonly used approach, but the inclusion of patients who were unable to recover from CRT would negatively impact the survival of the CRT cohort.

\section{Conclusions}

In summary, our study indicates that durable survival can be achieved in between a quarter and third of patients early-stage esophageal cancers treated with definitive CRT. Further study is needed to better inform shared decision making in patients interested in nonsurgical options but are ineligible for endoscopic management.

\section{Acknowledgments}

Funding: None.

\section{Footnote}

Reporting Checklist: The authors have completed the STROBE guideline checklist Available at http://dx.doi. org/10.21037/jtd-20-1187

Conflicts of Interest: All authors have completed the ICMJE uniform disclosure form (available at http://dx.doi. org/10.21037/jtd-20-1187). The authors have no conflicts of interest to declare.

Ethical Statement: The authors are accountable for all aspects of the work in ensuring that questions related 
to the accuracy or integrity of any part of the work are appropriately investigated and resolved. All procedures performed in studies involving human participants were in accordance with the ethical standards of the institutional and/or national research committee(s) and with the Helsinki Declaration (as revised in 2013). The NCDB uses de-identified data and was therefore deemed exempt by the Yale University Institutional Review Board.

Open Access Statement: This is an Open Access article distributed in accordance with the Creative Commons Attribution-NonCommercial-NoDerivs 4.0 International License (CC BY-NC-ND 4.0), which permits the noncommercial replication and distribution of the article with the strict proviso that no changes or edits are made and the original work is properly cited (including links to both the formal publication through the relevant DOI and the license). See: https://creativecommons.org/licenses/by-nc-nd/4.0/.

\section{References}

1. Bray F, Ferlay J, Soerjomataram I, et al. Global cancer statistics 2018: GLOBOCAN estimates of incidence and mortality worldwide for 36 cancers in 185 countries. CA Cancer J Clin 2018;68:394-424.

2. Lambert $R$, Hainaut $P$. The multidisciplinary management of gastrointestinal cancer. Epidemiology of oesophagogastric cancer. Best Pract Res Clin Gastroenterol 2007;21:921-45.

3. Zhang Y. Epidemiology of esophageal cancer. World J Gastroenterol 2013;19:5598-606.

4. Sohda M, Kuwano H. Current Status and Future Prospects for Esophageal Cancer Treatment. Ann Thorac Cardiovasc Surg 2017;23:1-11.

5. National Comprehensive Cancer Network. Esophageal and Esophagogastric Junction Cancers. Version 2.2019.

6. Wright CD, Kucharczuk JC, O’Brien SM, et al. Predictors of major morbidity and mortality after esophagectomy for esophageal cancer: A Society of Thoracic Surgeons General Thoracic Surgery Database risk adjustment model. J Thorac Cardiovasc Surg 2009;137:587-95.

7. Chiu AS, Arnold B, Hoag J, et al. Quality Versus Quantity: The Potential Impact of Public Reporting of Hospital Safety for Complex Cancer Surgery. Ann Surg 2019;270:281-7.

8. Lordick F, Mariette C, Haustermans K, et al. Oesophageal cancer: ESMO Clinical Practice Guidelines for diagnosis, treatment and follow-up. Ann Oncol 2016;27:v50-7.
9. Mallin K, Browner A, Palis B, et al. Incident Cases Captured in the National Cancer Database Compared with Those in U.S. Population Based Central Cancer Registries in 2012-2014. Ann Surg Oncol 2019;26:1604-12.

10. von Elm E, Altman DG, Egger M, et al. The Strengthening the Reporting of Observational Studies in Epidemiology (STROBE) Statement: Guidelines for Reporting Observational Studies. PLoS Med 2007;4:e296.

11. Boffa DJ, Rosen JE, Mallin K, et al. Using the National Cancer Database for Outcomes Research: A Review. JAMA Oncol 2017;3:1722-8.

12. Sterne JAC, White IR, Carlin JB, et al. Multiple imputation for missing data in epidemiological and clinical research: potential and pitfalls. BMJ 2009;338:b2393.

13. Multiple Imputation for Nonresponse in Surveys I Wiley [Internet]. Wiley.com. [cited 2019 Nov 20]. Available online: https://www.wiley.com/en-us/Multiple+Imputation +for+Nonresponse+in+Surveys-p-9780471655749

14. American College of Surgeons. The National Cancer Database 2016 PUF Data Dictionary. Accessed January 1, 2020. [Internet]. [cited 2019 Jul 12]. Available online: http://ncdbpuf.facs.org/

15. Heinze G, Wallisch C, Dunkler D. Variable selection - A review and recommendations for the practicing statistician. Biom J 2018;60:431-49.

16. Panageas KS, Schrag D, Riedel E, et al. The effect of clustering of outcomes on the association of procedure volume and surgical outcomes. Ann Intern Med 2003;139:658-65.

17. Wani S, Drahos J, Cook MB, et al. Comparison of endoscopic therapies and surgical resection in patients with early esophageal cancer: a population-based study. Gastrointest Endosc 2014;79:224-232.e1.

18. Manner H, Pech O, Heldmann Y, et al. Efficacy, Safety, and Long-term Results of Endoscopic Treatment for Early Stage Adenocarcinoma of the Esophagus With Low-risk sm1 Invasion. Clin Gastroenterol Hepatol 2013;11:630-5.

19. Tian J, Prasad GA, Lutzke LS, et al. Outcomes of T1b esophageal adenocarcinoma patients. Gastrointest Endosc 2011;74:1201-6.

20. Prasad GA, Wu TT, Wigle DA, et al. Endoscopic and surgical treatment of mucosal (T1a) esophageal adenocarcinoma in Barrett's esophagus. Gastroenterology 2009; 137:815-23.

21. Semenkovich TR, Panni RZ, Hudson JL, et al. Comparative effectiveness of upfront esophagectomy versus induction chemoradiation in clinical stage T2N0 esophageal cancer: A decision analysis. J Thorac 
Cardiovasc Surg 2018;155:2221-2230.e1.

22. Stahl M, Stuschke M, Lehmann N, et al. Chemoradiation With and Without Surgery in Patients With Locally Advanced Squamous Cell Carcinoma of the Esophagus. J Clin Oncol 2005;23:2310-7.

23. Bedenne L, Michel P, Bouché O, et al. Chemoradiation Followed by Surgery Compared With Chemoradiation Alone in Squamous Cancer of the Esophagus: FFCD 9102. J Clin Oncol 2007;25:1160-8.

24. Abrams JA, Buono DL, Strauss J, et al. Esophagectomy Compared to Chemoradiation for Early Stage Esophageal Cancer in the Elderly. Cancer 2009;115:4924-33.

25. Adams R, Morgan M, Mukherjee S, et al. A prospective comparison of multidisciplinary treatment of oesophageal

Cite this article as: Pathak R, Canavan ME, Walters S, Salazar MC, Boffa DJ. Chemoradiation as a nonsurgical treatment option for early-stage esophageal cancers: a retrospective cohort study. J Thorac Dis 2021;13(1):140-148. doi: 10.21037/jtd-201187 cancer with curative intent in a UK cancer network. Eur J Surg Oncol 2007;33:307-13.

26. Matsuda S, Tsubosa Y, Niihara M, et al. Comparison of transthoracic esophagectomy with definitive chemoradiotherapy as initial treatment for patients with esophageal squamous cell carcinoma who could tolerate transthoracic esophagectomy. Ann Surg Oncol 2015;22:1866-73.

27. Yamashita H, Nakagawa K, Yamada K, et al. A single institutional non-randomized retrospective comparison between definitive chemoradiotherapy and radical surgery in 82 Japanese patients with resectable esophageal squamous cell carcinoma. Dis Esophagus 2008;21:430-6. 
Supplementary

Table S1 Cox proportional hazards model of cT1-2N0M0 patients undergoing definitive chemoradiation.

\begin{tabular}{|c|c|c|}
\hline Covariate & $\mathrm{HR}(95 \% \mathrm{Cl})$ & $P$ value \\
\hline \multicolumn{3}{|l|}{ Age category } \\
\hline$<65$ & [Reference] & \\
\hline 65 to 74 & $1.023(0.97-1.07)$ & 0.35 \\
\hline$\geq 75$ & $1.13(1.06-1.20)$ & $<0.001$ \\
\hline \multicolumn{3}{|l|}{ Sex } \\
\hline Male & [Reference] & \\
\hline Female & $0.84(0.81-0.89)$ & $<0.001$ \\
\hline \multicolumn{3}{|l|}{ Race } \\
\hline White & [Reference] & \\
\hline Non-white & $0.98(0.93-1.04)$ & 0.58 \\
\hline \multicolumn{3}{|l|}{ Origin } \\
\hline Non-Hispanic & [Reference] & \\
\hline Hispanic & $0.85(0.77-0.95)$ & 0.003 \\
\hline Unknown & $0.97(0.91-1.04)$ & 0.47 \\
\hline \multicolumn{3}{|l|}{ Insurance } \\
\hline Not insured & $1.25(1.14-1.36)$ & $<0.001$ \\
\hline Private insurance & [Reference] & \\
\hline Medicaid & $1.28(1.19-1.36)$ & $<0.001$ \\
\hline Medicare & $1.11(1.06-1.17)$ & $<0.001$ \\
\hline Other government & $1.02(0.91-1.16)$ & 0.64 \\
\hline Unknown & $1.21(1.04-1.40)$ & 0.01 \\
\hline \multicolumn{3}{|l|}{ Facility location } \\
\hline Northeast & [Reference] & \\
\hline Midwest & $1.04(1.00-1.10)$ & 0.04 \\
\hline South & $1.08(1.03-1.13)$ & $<0.001$ \\
\hline West & $1.02(0.96-1.08)$ & 0.35 \\
\hline \multicolumn{3}{|l|}{ Area of residence ${ }^{a}$} \\
\hline Rural & $0.97(0.86-1.10)$ & 0.71 \\
\hline Urban & $1.04(0.99-1.10)$ & 0.06 \\
\hline Metropolitan & [Reference] & \\
\hline Unknown & $0.98(0.89-1.09)$ & 0.83 \\
\hline \multicolumn{3}{|l|}{ Distance } \\
\hline$\leq 10$ & [Reference] & \\
\hline 10 to 20 & $0.99(0.94-1.03)$ & 0.73 \\
\hline 20 to 50 & $0.92(0.88-0.97)$ & 0.002 \\
\hline 50 to 100 & $0.86(0.80-0.93)$ & $<0.001$ \\
\hline
\end{tabular}

Table S1 (continued)
Table S1 (continued)

\begin{tabular}{|c|c|c|}
\hline Covariate & $\mathrm{HR}(95 \% \mathrm{Cl})$ & $P$ value \\
\hline$>100$ & $0.79(0.73-0.85)$ & $<0.001$ \\
\hline \multicolumn{3}{|l|}{ Median income } \\
\hline$<38000$ & $1.03(0.96-1.10)$ & 0.34 \\
\hline 38000 to 47999 & $1.01(0.94-1.06)$ & 0.83 \\
\hline 48000 to 62999 & $1.04(0.99-1.09)$ & 0.07 \\
\hline$>63000$ & [Reference] & \\
\hline Unknown & $1.14(0.59-2.20)$ & 0.69 \\
\hline \multicolumn{3}{|l|}{ Education, $\%^{\mathrm{b}}$} \\
\hline$\geq 21$ & $1.07(0.99-1.15)$ & 0.07 \\
\hline 13 to 20.9 & $1.04(0.98-1.11)$ & 0.12 \\
\hline 7 to 12.9 & $1.01(0.96-1.06)$ & 0.61 \\
\hline$<7$ & [Reference] & \\
\hline Unknown & $1.05(0.51-2.17)$ & 0.88 \\
\hline \multicolumn{3}{|l|}{ Histology } \\
\hline Adenocarcinoma & [Reference] & \\
\hline $\begin{array}{l}\text { Squamous cell } \\
\text { carcinoma }\end{array}$ & $1.12(1.06-1.17)$ & $<0.001$ \\
\hline Other & $1.19(1.10-1.30)$ & $<0.001$ \\
\hline \multicolumn{3}{|l|}{ Primary site } \\
\hline Upper esophagus & $0.82(0.75-0.90)$ & $<0.001$ \\
\hline Middle esophagus & [Reference] & \\
\hline Lower esophagus & $0.90(0.85-0.95)$ & $<0.001$ \\
\hline Overlapping & $1.12(1.02-1.22)$ & 0.01 \\
\hline Esophagus, NOS & $0.93(0.86-0.99)$ & 0.05 \\
\hline \multicolumn{3}{|l|}{ Grade } \\
\hline Well differentiated & [Reference] & \\
\hline $\begin{array}{l}\text { Moderately } \\
\text { differentiated }\end{array}$ & $1.17(1.08-1.28)$ & $<0.001$ \\
\hline $\begin{array}{l}\text { Poorly differentiated or } \\
\text { undifferentiated }\end{array}$ & $1.39(1.28-1.52)$ & $<0.001$ \\
\hline
\end{tabular}

Table S1 (continued) 
Table S1 (continued)

\begin{tabular}{|c|c|c|}
\hline Covariate & $\mathrm{HR}(95 \% \mathrm{Cl})$ & $P$ value \\
\hline \multicolumn{3}{|c|}{ Year of diagnosis } \\
\hline 2004 & [Reference] & \\
\hline 2005 & $0.98(0.90-1.09)$ & 0.82 \\
\hline 2006 & $0.97(0.89-1.07)$ & 0.54 \\
\hline 2007 & $0.93(0.84-1.02)$ & 0.11 \\
\hline 2008 & $0.93(0.85-1.02)$ & 0.13 \\
\hline 2009 & $0.85(0.77-0.93)$ & $<0.001$ \\
\hline 2010 & $0.86(0.78-0.95)$ & $<0.001$ \\
\hline 2011 & $0.79(0.72-0.87)$ & $<0.001$ \\
\hline 2012 & $0.79(0.72-0.87)$ & $<0.001$ \\
\hline 2013 & $0.82(0.74-0.89)$ & $<0.001$ \\
\hline 2014 & $0.76(0.69-0.84)$ & $<0.001$ \\
\hline 2015 & $0.80(0.73-0.88)$ & $<0.001$ \\
\hline \multicolumn{3}{|c|}{ Refused recommended surgery } \\
\hline No & [Reference] & \\
\hline Yes & $0.64(0.57-0.73)$ & $<0.001$ \\
\hline \multicolumn{3}{|c|}{ Charlson-Deyo score } \\
\hline 0 & [Reference] & \\
\hline 1 & $1.08(1.04-1.13)$ & $<0.001$ \\
\hline$\geq 2$ & $1.14(1.06-1.22)$ & $<0.001$ \\
\hline
\end{tabular}

${ }^{a}$ Based on patient's zip code area; ${ }^{b}$ Percent of people in the patient's zip code area with no high-school diploma. 